\title{
Microvascular changes in macula and optic nerve head after femtosecond laser- assisted LASIK: an optical coherence tomography angiography study
}

\author{
Yan Zhang ${ }^{\dagger}$, Jianqing Lan ${ }^{\dagger}$, Dan Cao, Cheng Yang, Dawei Yang, Wenjuan Xie and Jin Zeng*
}

\begin{abstract}
Background: To measure the microcirculation change of macula and optic nerve head before and after femtosecond laser assisted laser in situ keratomileusis.

Methods: In total 45 eyes from 45 subjects, who underwent FS-LASIK during June 2017 to December 2017 in Guangdong Provincial People's Hospital, were recruited in this study. Vessel density in macula and optic nerve head were measured by optical coherence tomography angiography before and after transient elevation in intraocular pressure caused by application of suction ring during surgery.

Results: Vessel density (VD) at superficial $(S C P)$ plexus of macular region did not differ after surgery $(F(3,132)=1.41$, $P=0.24)$, while the deep (DCP) plexus of macular region significantly decreased 1 day after surgery $(P=0.001)$ but returned to its baseline value 1 month postoperatively $(P=0.1)$. Vessel density of optic nerve head region had no significant changes after surgery $(F(2.51,95.18)=0.6, P=0.59)$.

Conclusions: A short-term temporary decrease of vessel density at deep layer of macular region was observed in eyes undergoing FS-LASIK. However, the retinal capillary density went back to preoperative level 1 month after surgery. Therefore, transient IOP spike during FS-LASIK did not cause long-term decline of retinal microcirculation.
\end{abstract}

\section{Background}

Femtosecond laser assisted laser in situ keratomileusis (LASIK) is currently one of the most commonly performed refractive surgery worldwide. During the surgery, a suction ring is applied on the anterior segments of the eye in order to immobilize the eyeball. IOP could be elevated to more than $90 \mathrm{mmHg}[1-3]$ in the vacuum affixation phase and return to normal after the suction ring was removed. Investigation revealed that sudden increase of IOP caused a temporary central retinal artery

\footnotetext{
* Correspondence: syzengjin@scut.edu.cn

${ }^{\dagger}$ Yan Zhang and Jianqing Lan contributed equally to this work. Department of Ophthalmology, Guangdong Eye Institute, Guangdong Provincial People's Hospital, Guangdong Academy of Medical Sciences, No. 106 Zhongshan Er Road, Guangzhou 510080, China
}

occlusion during the suction phase [4] and lead to a stop of retinal circulation. Potential ocular complications occur overtimes. Solitary cases of nonarteritic ischemic optic neuropathy (NAION) [5], iris atrophy [6], macular edema [7], macular hemorrhage [8] after LASIK were reported.

Previous study has investigated a temporary increase in blood flow at the lamina cribrosa region of the optical nerve head after surgery [9]. While the change of macular blood flow was currently unknown. Optical coherence tomography angiography (OCTA) is a new noninvasive technique that can visualize the retinal vascular network and quantify the vascular density in the macular area and optical nerve head $(\mathrm{ONH})$. In this study, microcirculation in the macula and $\mathrm{ONH}$ were

(C) The Author(s). 2020 Open Access This article is licensed under a Creative Commons Attribution 4.0 International License, which permits use, sharing, adaptation, distribution and reproduction in any medium or format, as long as you give appropriate credit to the original author(s) and the source, provide a link to the Creative Commons licence, and indicate if changes were made. The images or other third party material in this article are included in the article's Creative Commons licence, unless indicated otherwise in a credit line to the material. If material is not included in the article's Creative Commons licence and your intended use is not permitted by statutory regulation or exceeds the permitted use, you will need to obtain permission directly from the copyright holder. To view a copy of this licence, visit http://creativecommons.org/licenses/by/4.0/ The Creative Commons Public Domain Dedication waiver (http://creativecommons.org/publicdomain/zero/1.0/) applies to the data made available in this article, unless otherwise stated in a credit line to the data. 


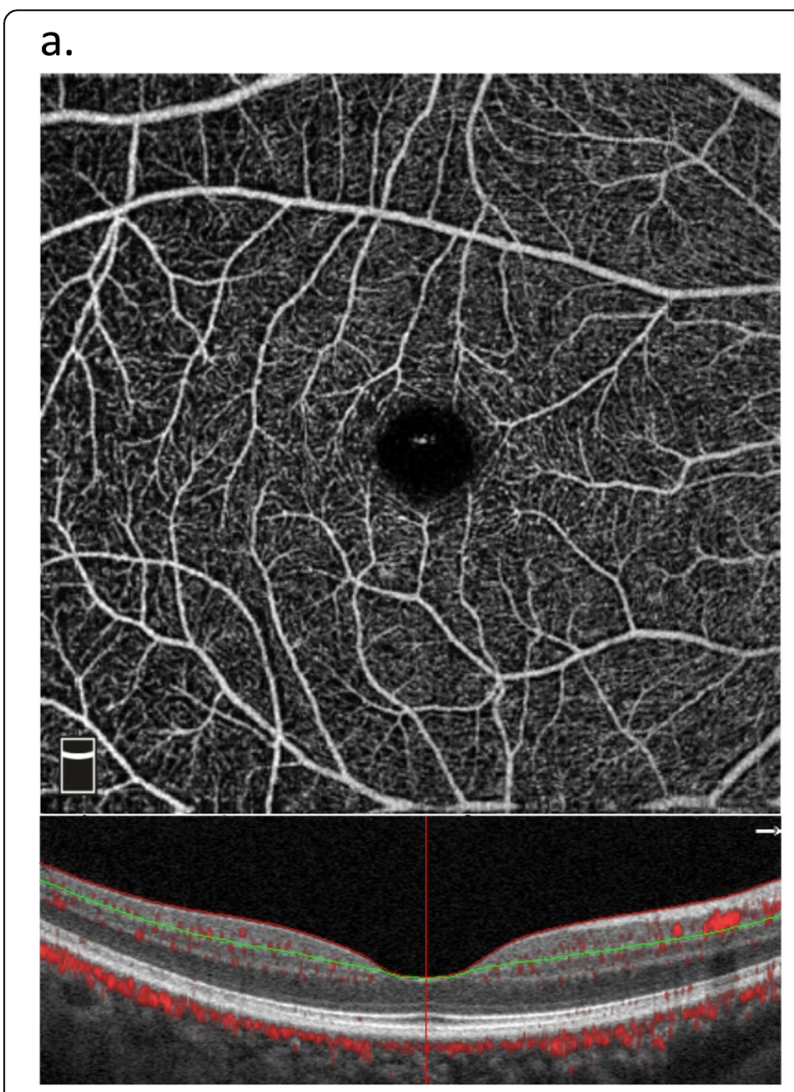

b.

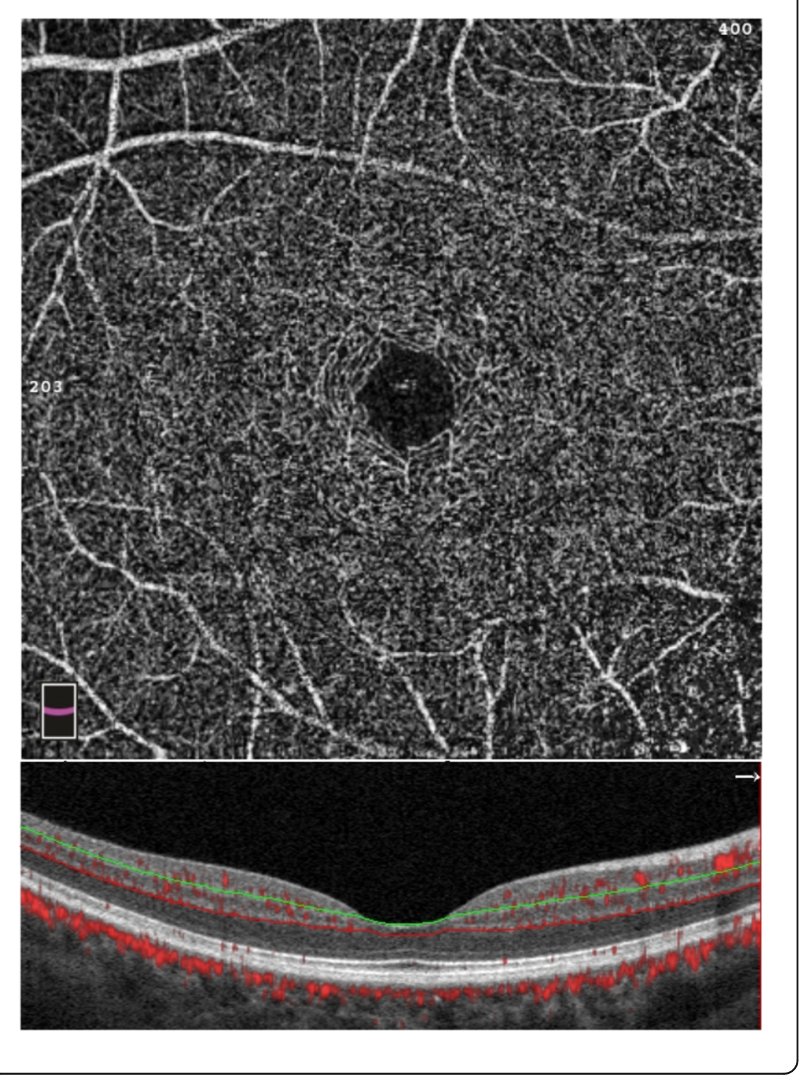

Fig. 1 Example of vessel density image of superficial plexus (a) and deep plexus (b)

measured by OCTA to investigate the retinal blood change before and after the surgery.

\section{Methods}

This prospective study was conducted from June 2017 to December 2017 at Guangdong Provincial People's Hospital. A total of 48 patients were recruited in this study, one eye of each subject was randomly selected by a process of alternation. The research protocols were approved by the Institutional Review Broad at Guangdong Provincial People's Hospital. The study followed the tenets of the Declaration of Helsinki and all subjects were thoroughly informed of the procedure and provided written informed consent.

The inclusion criteria for the surgery were as follows: patients were willing to receive the surgery and had good compliance and cognitive ability, age of 18 or older, stable refraction for at least 2 years, refractive error not greater than -8.0 diopters (D) sphere or $-4.0 \mathrm{D}$ of astigmatism, no history of ocular surgery or any other ocular or systemic diseases. Eyes with possible keratoconus were excluded by using the keratoconus screening test of Pentacam HR(Oculus, Germany).

\section{Surgical procedures}

All surgeries were performed by the same experienced surgeon (J.Z.). A suction ring was applied to the anterior segment of the eye in order to immobilize the eyeball, after which an 8.4 to $8.5 \mathrm{~mm}$ flap of 100 um thickness was cut with the femtosecond laser (IntraLase iFS 150, Abbott Medical Optics Inc., Santa Ana, California). The flap was separated and lifted, followed by ablation in a 6.0 to 6.2 $\mathrm{mm}$ optical zone using the Wavefront-guided excimer laser (Technolas 217z100 excimer laser platform, Bausch \& Lomb, Rochester, NY). After repositioning the flap, postoperative topical medications were given.

\section{OCTA imaging}

The RTVueXR Avanti device (V.2017.1.0.121; RTVueXR Avanti; Optovue, Inc., Fremont, CA, USA) is a new noninvasive imaging device utilizing SSADA (split-spectrum amplitude-decorrelation angiography) to detect vessels and blood flow through the motion provided by flowing erythrocytes. All patients received OCTA examination before and 1 day/ 1 week/ 1 month after surgery and all examinations were performed by the same ophthalmologist (Y.Z).

We selected the macular HD $6 \times 6 \mathrm{~mm}$ program with a scanning area centered on macula to evaluate macular microcirculation. The image was automatically divided into the superficial capillary plexuses (SCP) and deep 
capillary plexuses (DCP). Seen in Fig. 1. SCP is defined as a lamina extending from internal limiting membrane (ILM) to $10 \mu \mathrm{m}$ above inner plexiform layer (IPL) while DCP is the lamina extending from $10 \mu \mathrm{m}$ above IPL to $10 \mu \mathrm{m}$ below outer plexiform layer (OPL). Vessel density (\%) was quantified automatically by the inner software of OCT system. Besides, the software automatically fits a circle $(1.0 \mathrm{~mm}$ in diameter) centered on the fovea. The parafovea region is defined as a $2.0 \mathrm{~mm}$ wide round annulus around the fovea and the perifovea region is defined as a $3.0 \mathrm{~mm}$ wide round annulus around the parafovea. Seen in Fig. 2.

To evaluate blood flow of optic nerve head $(\mathrm{ONH})$, a HD disc $4.5 \times 4.5 \mathrm{~mm}$ program was acquired and vessel density (\%) was quantified automatically by the OCT system. The software automatically fits a circle $(2 \mathrm{~mm}$ in diameter) centered on the optic disc and the peripapillary region is defined as a $1.0 \mathrm{~mm}$ wide round annulus around the optic disc $2.0 \mathrm{~mm}$ circle [10]. Seen in Fig. 3.

Poor quality images with a scan quality less than 7 were excluded from analysis. Therefore, data of 3 of our patients were excluded.

\section{Statistical analysis}

Qualified data were processed and analyzed with SPSS for Mac software (Version 25.0; SPSS, Chicago, IL). All data were normal distributed confirmed by a KolmogorovSmirnoff test. Measurements before surgery was compared with measurements 1 day/1 week/1 month after surgery respectively using the repeated-measures analysis. $P<0.05$ was considered statistically significant.

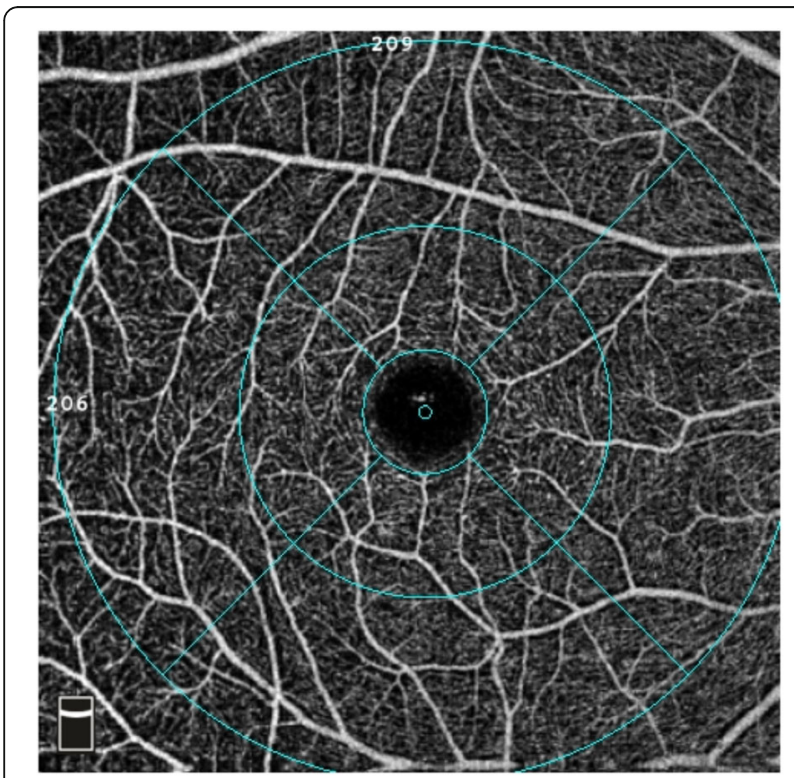

Fig. 2 Macular vessel density was automatically labeled as the fovea, parafoveal and perifoveal region

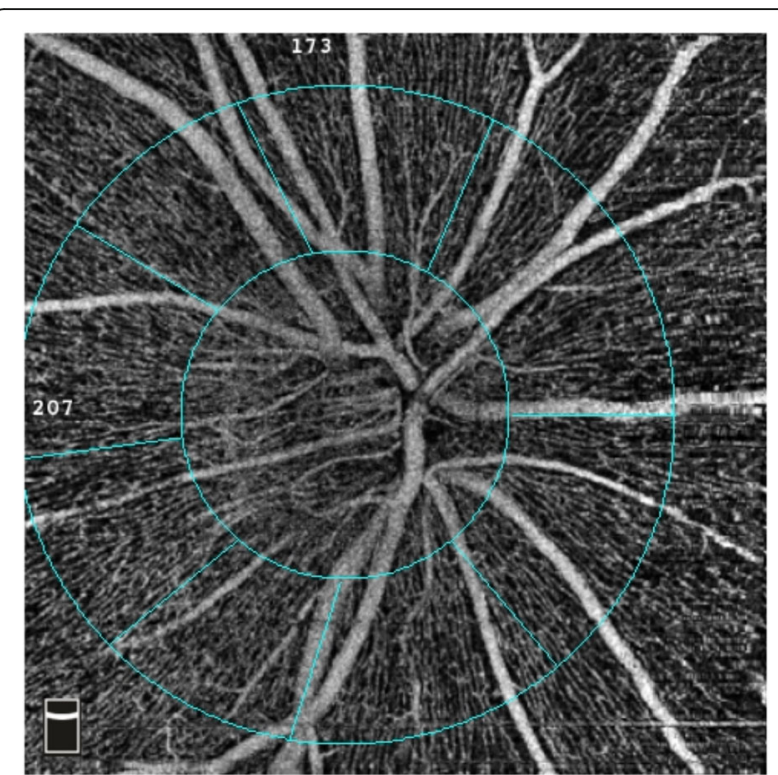

Fig. 3 Example of an optic nerve head vessel density image. The software automatically fits the optic disc region and peripapillary region

\section{Results}

The study included 45 eyes of 45 individuals who received FS-LASIK in our hospital. There were 15 male and $30 \mathrm{fe}-$ male patients with average age of $27.1 \pm 4.44$ years (range: 21 to 40 years). Preoperative spherical equivalent were $5.66 \pm 2.18 \mathrm{D}$ (range: $-8.25 \mathrm{D}$ to $-1.50 \mathrm{D}$ ) with a spherical refraction of $-5.31 \pm 2.15 \mathrm{D}$ (range: $-8.00 \mathrm{D}$ to $-1.50 \mathrm{D}$ ) and a cylindrical refraction of $-0.82 \pm 0.69 \mathrm{D}$ (range: $2.25 \mathrm{D}$ to $0.50 \mathrm{D}$ ). The duration of suction ring application in surgery were $51.75 \pm 14.4 \mathrm{~s}$ (range: 38 to $93 \mathrm{~s}$ ). Seen in Table. 1.

Vessel density (VD) of whole $6 \times 6 \mathrm{~mm}$ macular image in the SCP and DCP were $50.84 \pm 0.4 \%$ and $52.95 \pm 0.74 \%$ respectively before surgery. The VD of whole macular image in SCP decreased after surgery, but the changes were not significant $(F(3,132)=1.41, P=0.24)$. VD of the whole macular image at DCP showed significant decrease 1 day and 1 week after surgery $(49.64 \pm 0.81 \%, P=0.001$ at 1 day, $50.46 \pm 0.91 \%, P=0.022$ at 1 week) and returned to

Table 1 Baseline characteristics

\begin{tabular}{ll}
\hline Characteristics & Mean \pm Standard Deviation \\
\hline Age & $27.1 \pm 4.44$ years \\
Gender & 15 males: 30 females \\
Manifest refraction (D) & \\
$\quad$ Sphere & $-5.31 \pm 2.15 \mathrm{D}$ \\
Cylinder & $-0.82 \pm 0.69 \mathrm{D}$ \\
Spherical equivalent & $-5.66 \pm 2.18 \mathrm{D}$ \\
$\quad$ Suction time & $51.75 \pm 14.4 \mathrm{~s}$ \\
\hline
\end{tabular}


its preoperative level 1 month after surgery $(51.4 \pm 0.81 \%$, $P=0.102)$. Measurements of the VD of foveal, parafoveal and perifoveal regions in SCP and DCP were shown in Table 2 and Table 3.

VD in the whole $4.5 \times 4.5 \mathrm{~mm}$ ONH region showed no significant change before and after surgery $(\mathrm{F}(2.51$, $95.18)=0.6, P=0.588)$. However, a decrease in VD values inside the disc was observed 1 day after surgery $(P=$ $0.003)$, and the vessel density returned to its preoperative level 1 week after surgery $(P=0.098)$. VD in the peripapillary area did not change significantly after the FS-LASIK $(\mathrm{F}(2.93,90.75)=1.44, P=0.24)$. (Table 4.) The tendency of vessel density in whole image of SCP, DCP and ONH was shown in Fig. 4.

\section{Discussion}

By modifying the central corneal curvature, LASIK is frequently used for correcting refractive errors. Before the first clinical use of femtosecond laser for LASIK flap creation in 2001 [11], the corneal flap was created by a mechanical microkeratome. Femtosecond laser has a high laser frequency, which permits lower energy per pulse and tighter line separation, thereby creating a smoother corneal flap and resulting in faster visual recovery [12-14]. Besides, the rapid development of femtosecond $\left(10^{-15} \mathrm{~s}\right)$ lasers over the past two decades has opened up new applications in ophthalmic surgery [12] such as FLEx (FS laser lenticular extraction), SMILE (small-incision lenticular extraction), FLACS (FS laserassisted cataract surgery), etc. Many studies have revealed significant IOP increases during FS laser-assisted procedures [15-17]. In spite of changes in intraocular pressure, a phenomenon called retinal autoregulation [18-21] is able to maintain blood flow and oxygen supply to the fundus at a constant level. Rats experiments have [22] observed that as the intraocular pressure in-

Table 2 Vessel density (VD) (Mean \pm SD) of macular superficial plexus at baseline and 1 day/1 week/1 month after FS-LASIK

\begin{tabular}{lllll}
\hline & $\begin{array}{l}\text { Baseline } \\
\text { (mean } \pm \\
\text { SD) } \%\end{array}$ & $\begin{array}{l}\text { 1 day } \\
\text { (mean } \pm \text { SD) }\end{array}$ & $\begin{array}{l}\text { 1 week } \\
(\text { mean } \pm \text { SD) } \\
\%\end{array}$ & $\begin{array}{l}1 \text { month } \\
\text { (mean } \pm \text { SD) } \\
\%\end{array}$ \\
\hline $\begin{array}{l}\text { Whole area } \\
\left(6^{*} 6 \mathrm{~mm}^{2}\right)\end{array}$ & $50.84 \pm 0.4$ & $49.98 \pm 0.39$ & $50.06 \pm 0.49$ & $50.42 \pm 0.47$ \\
Fovea Region & $21.66 \pm 1.01$ & $20.03 \pm 1.01^{*}$ & $19.97 \pm 0.97^{*}$ & $20.06 \pm 0.94^{*}$ \\
$\begin{array}{l}\text { Parafovea } \\
\text { Region }\end{array}$ & $53.31 \pm 0.54$ & $51.73 \pm 0.49$ & $51.89 \pm 0.67$ & $52.54 \pm 0.6$ \\
$\begin{array}{l}\text { Perifovea } \\
\text { Region }\end{array}$ & $51.56 \pm 0.41$ & $50.77 \pm 0.43$ & $50.76 \pm 0.49$ & $51.09 \pm 0.49$ \\
\hline
\end{tabular}

VD at baseline was compared with VD at 1 day/1 week/1 month respectively using the repeated-measures analysis. The VD of whole area of SPC had no significantly change after surgery $(F(3,132)=1.41, P=0.24)$. The preoperative VD of fovea region was significantly difference from the VD at 1 day/1 week/1 month after surgery $(F=(2.71,118.83)=9.72, P<0.001)$. VD at 1 day $/ 1$ week $/ 1$ month after surgery decreased significantly $(P<0.001)$. VD of parafovea and perifovea region did not change postoperatively $(F(3,132)=2.27, P=0.08$; $\mathrm{F}(3,132)=1.23, P=0.301$, respectively). * represented $P<0.05$
Table 3 Vessel density (VD) (Mean \pm SD) of macular deep plexus at baseline and 1 day/1 week/1 month after FS-LASIK

\begin{tabular}{lllll}
\hline & $\begin{array}{l}\text { Baseline } \\
(\text { mean } \pm \\
\text { SD) } \%\end{array}$ & $\begin{array}{l}1 \text { day } \\
(\text { mean } \pm \text { SD })\end{array}$ & $\begin{array}{l}1 \text { week } \\
(\text { mean } \pm S D) \\
\%\end{array}$ & $\begin{array}{l}1 \text { month } \\
(\text { mean } \pm \text { SD }) \\
\%\end{array}$ \\
\hline $\begin{array}{l}\text { Whole area } \\
\left(6^{*} 6 \mathrm{~mm}^{2}\right)\end{array}$ & $52.95 \pm 0.74$ & $49.64 \pm 0.81^{*}$ & $50.46 \pm 0.91^{*}$ & $51.4 \pm 0.81$ \\
$\begin{array}{l}\text { Fovea Region } \\
\text { Parafovea }\end{array}$ & $38.22 \pm 1.17$ & $36.14 \pm 1.19^{*}$ & $36.21 \pm 1.2^{*}$ & $36.35 \pm 1.17^{*}$ \\
$\begin{array}{l}\text { Region } \\
\begin{array}{l}\text { Perifovea } \\
\text { Region }\end{array}\end{array}$ & $58.27 \pm 0.49$ & $55.56 \pm 0.56^{*}$ & $55.91 \pm 0.8^{*}$ & $56.93 \pm 0.54^{*}$ \\
\hline
\end{tabular}

VD at baseline was compared with VD at 1 day/1 week/1 month respectively using the repeated-measures analysis. The VD of whole area of DPC significantly differ after surgery $(F(3,132)=4.45, P=0.005)$. Vessel density was decreased 1 day after surgery $(P=0.001, P=0.022$ at 1 week and 1 month respectively) and gradually recovered to its normal range in 1 month $(P=$ 0.102 ). The preoperative $V D$ of fovea region was significantly difference from the $V D$ at 1 day $/ 1$ week $/ 1$ month after surgery $(F=(3132)=11.73, P<0.001)$. VD at 1 day/1 week/1 month after surgery decreased significantly $(P<0.001)$. VD of parafovea region significantly changed after surgery $(F(2.71,119.26)=5.13, P=$ $0.003)$. Vessel density of parafovea region was decreased after surgery $(P<$ $0.001, P=0.01, P=0.039$ at 1 day $/ 1$ week $/ 1$ month respectively). The perifovea region also changed postoperatively $(F(3,132)=4.09, P=0.008)$. the vessel density was decreased at 1 day $(P=0.001)$ and gradually returned to its preoperatively level in 1 month $(P=0.04, P=0.142$ at 1 week and 1 month respectively). ${ }^{*}$ represented $P<0.05$

creased by $30 \mathrm{mmHg}$ to $100 \mathrm{mmHg}$, autoregulation was overwhelmed, and the retinal blood flow diminished linearly. Maximum IOP during corneal flap cutting with a femtosecond laser was reported vary from $27 \mathrm{mmHg}$ [23] to $328 \mathrm{mmHg}$ [16] by different researches. To our knowledge, this is the first study to investigate the retinal microcirculation changes associated with transient IOP spike caused by FS-LASIK in human.

In the present study, we found that macular vessel density of whole image at DCP descreased significantly in early recovery period after FS-LASIK, but VD returned to its preoperative value 1 month after surgery. However, VD of macular subregions at SCP and DCP showed significant change 1 month after surgery especially the foveal region at both layers and the parafoveal

Table 4 Vessel density (VD) (Mean \pm SD) of optic nerve head region at baseline and 1 day/1 week/1 month after FS-LASIK

\begin{tabular}{lllll}
\hline & $\begin{array}{l}\text { Baseline } \\
(\text { mean } \pm \\
\text { SD) } \%\end{array}$ & $\begin{array}{l}1 \text { day } \\
(\text { mean } \pm \\
\text { SD) } \%\end{array}$ & $\begin{array}{l}1 \text { week } \\
(\text { mean } \pm \\
\text { SD) } \%\end{array}$ & $\begin{array}{l}1 \text { month } \\
(\text { mean } \pm \\
\text { SD) } \%\end{array}$ \\
\hline $\begin{array}{l}\text { Whole area } \\
\left(4.5^{*} 4.5 \mathrm{~mm}^{2}\right)\end{array}$ & $49.32 \pm 0.34$ & $49.22 \pm 0.35$ & $49.17 \pm 0.41$ & $49.61 \pm 0.33$ \\
$\begin{array}{l}\text { Inside disc } \\
\text { region }\end{array}$ & $58.51 \pm 0.52$ & $56.6 \pm 0.65$ & $57.09 \pm 0.84$ & $58.61 \pm 0.67$ \\
$\begin{array}{l}\text { Peripapillary } \\
\text { Region }\end{array}$ & $51.16 \pm 0.42$ & $51.91 \pm 0.42$ & $51.76 \pm 0.43$ & $51.88 \pm 0.35$ \\
\hline $\begin{array}{l}\text { VD at baseline was compared with VD at } 1 \text { day/1 week/1 month respectively } \\
\text { using the repeated-measures analysis. VD of whole area ( }(2.51,95.18)=0.6,\end{array}$ \\
$\begin{array}{l}P=0.588), \text { inside disc region (F(2.32,88) }=5.38, P=0.08), \text { peripapillary region } \\
(F(2.39,90.75)=1.44, P=0.24) \text { of ONH did not differ after surgery }\end{array}$
\end{tabular}




\section{Vessel density changes before and after FS-LASIK}
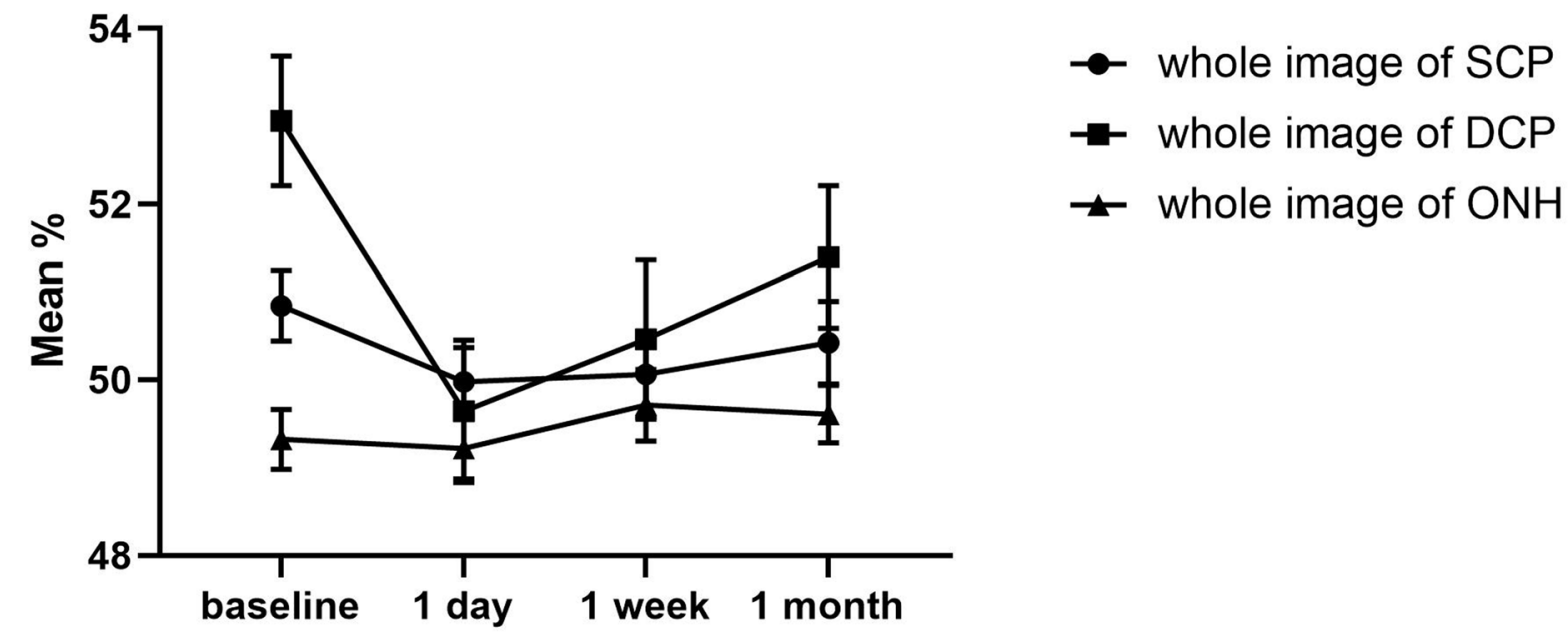

Fig. 4 Tendency of vessel density changes at the whole images of macular superficial capillary plexus (SCP), deep capillary plexus (DCP) and ONH (optic nerve head) before and after surgery

region at DCP (Table 2.). FS-LASIK did not significantly change vessel density at the whole $\mathrm{ONH}$ region.

Ozdamar et al. observed a temporary increase in blood flow at the lamina cribrosa region (choroidal blood flow) of the $\mathrm{ONH}$ by using Heidelberg Retinal Flowmeter, suggesting a compensatory change for maintaining blood flow in the ONH following Lasik-induced ischemia [9]. While Miriam et al. found that all blood-flow responses returned immediately to normal levels [3], including the systemic blood-flow and ocular blood-flow measured by Doppler imaging system. However, Doppler scanning system is insensitive to microcirculation, and visualization has typically been limited to major veins and arteries [24]. OCTA utilizes a Split-Spectrum Amplitude-Decorrelation Angiography (SSADA) algorithm which is more sensitive to microcirculation of the retina. In our study, a sudden change of IOP during corneal flap cutting did not affect the microcirculation in $\mathrm{ONH}$ region, which matched the results found by Miriam et al. compared with the mechanical microkeratome, femtosecond laser system employs a lower pressure suction ring to stabilize the globe [12] could be another reason why it did not affect the microcirculation in $\mathrm{ONH}$ region.

Previous study of blood flow during LASIK microkeratome ring found no blood-flow signal in the central retinal artery during the suction phase [4]. Usually, the only arterial blood supply to the inner retina is from the central retinal artery [25]. The artery divides to trunks and then branches to supply oxygen and nutrition to the inner retina. And the retinal venous branches are distributed in a relatively similar pattern. Branches from the central retinal vessels dive deep into the retina forming two distinct capillary beds, the superficial capillary plexus and the deep capillary plexus. The morphology and function of the retinal capillary layers are coupled with the metabolic demands of the neuronal retina. Animal model experiments [26, 27] have found that the dominant oxygen consumers of the inner retina are located in the plexiform layers, which are supplied by the DCP. This may explain the reason why macular VD at DCP decreased at the early period after surgery. The VD in DCP is more sensitive to the oxygen alterations caused by a sudden increase of IOP during surgery. Both the overall macular VD in SCP and DCP had no changes 1 month after surgery, suggesting that the sudden increase of IOP during femtosecond laser procedure in LASIK did not cause a long-term change of microcirculation in macular region. However, significant decrease of VD in fovea at both SCP and DCP and significant decrease of VD in parafoveal region at DCP were observed 1 day after surgery and remained significantly declined 1 month after surgery. Previous studies have found that LASIK for myopia significantly deteriorated contrast sensitivity and it took at least 6 months for recovery of contrast sensitivity (CS) [28]. It is known that change of the foveal microstructure may affect deterioration or improvement of CS [29]. The decrease of VD in fovea and parafoveal region may explain the deterioration of CS after LASIK. The relation between changes in macular vessel density and contrast sensitivity would be important in our future studies.

Limitations of this study include that the real-time IOP was unable to be measured because of an aseptic requirement in surgery and a limited space to operate 
measurement during the femtosecond procedure. Second, we did not perform OCTA immediately after surgery because the intense tearing and itching will affect the quality of images. Third, we could have added a control group of patients scheduled for LASEK, which a suction phase was not necessary during the surgery. But the regeneration of corneal epithelium after LASEK will affect the image quality of OCTA in early recovery. Last, a sufficiently lengthy period of follow-up observation would ensure that there would be no long-term damage to the microcirculation in macular and $\mathrm{ONH}$ region.

\section{Conclusion}

In conclusion, the sudden increase of IOP in FS-LASIK caused a temporary decrease of vessel density at the deep layer of macular region. Vessel density at optic nerve head region had no significant changes after surgery. Transient IOP spike during FS-LASIK did not cause long-term decline of retinal microcirculation after surgery. However, vessel density at the fovea and parafovea region of deep capillary plexus were declined and did not recover to their preoperative levels 1 month after surgery. Further investigation with a longer follow-up period will be needed to confirm no long-term damage would remain at the fovea and parafoveal region.

\section{Abbreviations}

CS: Contrast sensitivity; DCP: Deep capillary plexuses; FS-LASIK: Femtosecond laser assisted Laser in situ keratomileusis; OCTA: Optical coherence tomography angiography; ONH: Optic nerve head; SCP: Superficial capillary plexuses; VD: Vessel density

\section{Acknowledgements \\ The authors thank the patients who generously agreed to participate in this clinical study.}

\section{Authors' contributions}

YZ and JQL analyzed the data and wrote the original manuscript. DC revised the manuscript. CY, DWY and WJX collected the data. JZ performed the surgery and revised the manuscript. All authors read and approved the final manuscript.

\section{Funding}

This study was supported by the Major Program, International Science and Technology Cooperation Program of Science and Technology Program of Guangzhou, China (No. 201704020048). The funding body has no role in the design or the study and collection, analysis and interpretation of data.

\section{Availability of data and materials}

The datasets used and analyzed during the current study are available from the corresponding author on reasonable request.

\section{Ethics approval and consent to participate}

The research protocols were approved by the Institutional Review Broad at Guangdong Provincial People's Hospital. The study followed the tenets of the Declaration of Helsinki and all subjects were thoroughly informed of the procedure and provided written informed consent.

\section{Consent for publication}

Written informed consent were obtained from all the patients. Copies of the written consent are available for review by the editor of this journal.

\section{Competing interests}

The authors have no proprietary or commercial interest in any of the materials discussed in this article.

Received: 4 April 2019 Accepted: 4 March 2020

Published online: 17 March 2020

\section{References}

1. Bradley JC, McCartney DL, Craenen GA. Continuous intraocular pressure recordings during lamellar microkeratotomy of enucleated human eyes. J Cataract Refract Surg. 2007;33(5):869-72. https://doi.org/10.1016/j.jcrs.2007. 02.017 .

2. Hernández-Verdejo $J$, de Benito-Llopis L, Teus MA. Comparison of real-time intraocular pressure during laser in situ keratomileusis and epithelial laser in situ keratomileusis in porcine eyes. J Cataract Refract Surg. 2010;36(3):47782. https://doi.org/10.1016/j.jcrs.2009.09.040.

3. Conway ML, Wevill M, Benavente-Perez A, Hosking SL. Ocular blood-flow hemodynamics before and after application of a laser in situ keratomileusis ring. J Cataract Refract Surg. 2010;36(2):268-72. https://doi.org/10.1016/j.jcrs. 2009.09.013.

4. Schicke SH, Krumeich J, Duncker GIW, Scheibel S, Thielscher M. Retinal colour duplex scanning during LASIK-ring suction with different keratomes. Graefes Arch Clin Exp Ophthalmol. 2008;246(7):1009-15. https://doi.org/10. 1007/s00417-008-0796-5.

5. Maden A, Yilmaz S, Yurdakul NS. Nonarteritic ischemic optic neuropathy after LASIK with femtosecond laser flap creation. J Neuro-Ophthalmology. 2008;28(3):242-3.

6. Olcay K, Cakir A, Sagdic SK, Duzgun E, Yildirim Y. Bilateral Iris atrophy after the femtosecond assisted laser in situ Keratomileusis surgery. Case Rep Ophthalmol Med. 2015;2015:127806. https://doi.org/10.1155/2015/127806.

7. Yang B, Wang Z, Huang G. Transient macular edema after laser in-situ Keratomileusis. Eye Sci. 2003;19:20-4.

8. Principe AH, Lin DY, Small KW, Aldave AJ. Macular hemorrhage after laser in situ keratomileusis (LASIK) with femtosecond laser flap creation. Am J Ophthalmol. 2004;138(4):657-9. https://doi.org/10.1016/ j.ajo.2004.04.030.

9. Ozdamar A, Ocakoglu O. Optic nerve head blood flow using scanning laser Doppler flowmetry after laser in situ keratomileusis. J Refract Surg. 2003; 19(4):433-7 http://www.ncbi.nlm.nih.gov/entrez/query.fcgi?cmd= Retrieve\&db=PubMed\&dopt=Citation\&list_uids=12899474.

10. Cao D, Yang D, Huang Z, et al. Optical coherence tomography angiography discerns preclinical diabetic retinopathy in eyes of patients with type 2 diabetes without clinical diabetic retinopathy. Acta Diabetol. 2018;55(5):46977. https://doi.org/10.1007/s00592-018-1115-1.

11. Ratkay-Traub I, Juhasz T, Horvath C, et al. Ultra-short pulse (femtosecond) laser surgery: initial use in LASIK flap creation. Ophthalmol Clin N Am. 2001; 14(2):347-55 viii-ix.

12. Soong HK, Malta JB. Femtosecond Lasers in OphthalmologyAm J Ophthalmol. 2009;147(2):189-197.e2. https://doi.org/10.1016/j.ajo.2008.08. 026.

13. Chen S, Feng Y, Stojanovic A, Jankov MR, Wang Q. IntraLase femtosecond laser vs mechanical Microkeratomes in LASIK for myopia: a systematic review and meta-analysis. J Refract Surg. 2012;28(1):15-24. https://doi.org/ 10.3928/1081597X-20111228-02.

14. Kymionis GD, Kankariya VP, Plaka AD, Reinstein DZ. Femtosecond laser Technology in Corneal Refractive Surgery: a review. J Refract Surg. 2012; 28(12):912-20. https://doi.org/10.3928/1081597X-20121116-01.

15. Sperl $\mathrm{P}$, Strohmaier $\mathrm{C}$, Kraker $\mathrm{H}$, et al. Intraocular pressure course during the femtosecond laser-assisted cataract surgery in porcine cadaver eyes. Investig Ophthalmol Vis Sci. 2017;58(14):6457-61. https://doi.org/10.1167/ iovs.17-21948.

16. Strohmaier $C$, Runge $C$, Seyeddain $O$, et al. Profiles of intraocular pressure in human donor eyes during femtosecond laser procedures-a comparative study. Investig Ophthalmol Vis Sci. 2013;54(1):522-8. https://doi.org/10.1167/ iovs.12-11155.

17. Vetter JM, Schirra A, Garcia-Bardon D, Lorenz K, Weingärtner WE, Sekundo W. Comparison of intraocular pressure during corneal flap preparation between a femtosecond laser and a mechanical microkeratome in porcine eyes. Cornea. 2011;30(10):1150-4. https://doi.org/10.1097/ICO. ob013e318212110a. 
18. Liang Y, Fortune B, Cull G, Cioffi GA, Wang L. Quantification of dynamic blood flow autoregulation in optic nerve head of rhesus monkeys. Exp Eye Res. 2010;90(2):203-9. https://doi.org/10.1016/j.exer.2009.10.009.

19. Guidoboni G, Harris A, Cassani S, et al. Intraocular pressure, blood pressure, and retinal blood flow autoregulation: a mathematical model to clarify their relationship and clinical relevance. Investig Ophthalmol Vis Sci. 2014;55(7): 4105-18. https://doi.org/10.1167/iovs.13-13611.

20. Boltz A, Schmidl D, Werkmeister RM, et al. Regulation of optic nerve head blood flow during combined changes in intraocular pressure and arterial blood pressure. J Cereb Blood Flow Metab. 2013;33(12):1850-6. https://doi. org/10.1038/jcbfm.2013.137.

21. Zhang $\mathrm{Q}$, Jonas JB, Wang $\mathrm{Q}$, et al. Optical coherence tomography angiography vessel density changes after acute intraocular pressure elevation. Sci Rep. 2018;8(1):1-8. https://doi.org/10.1038/s41598-018-24520-x.

22. Zhi Z, Cepurna W, Johnson E, Jayaram H, Morrison J, Wang RK. Evaluation of the effect of elevated intraocular pressure and reduced ocular perfusion pressure on retinal capillary bed filling and total retinal blood flow in rats by OMAG/OCT. Microvasc Res. 2015;101:86-95. https://doi.org/10.1016/j.mvr. 2015.07.001.

23. Ang M, Chaurasia SS, Angunawela Rl, et al. Femtosecond lenticule extraction (FLEx): clinical results, interface evaluation, and intraocular pressure variation. Investig Ophthalmol Vis Sci. 2012:53(3):1414-21. https:// doi.org/10.1167/iovs.11-8808

24. Kashani AH, Chen CL, Gahm JK, et al. Optical coherence tomography angiography: A comprehensive review of current methods and clinical applications. Prog Retin Eye Res. 2017;60:66-100. https://doi.org/10.1016/j. preteyeres.2017.07.002.

25. Anand-Apte B, Hollyfield JG. Developmental anatomy of the retinal and choroidal vasculature. Encycl Eye. 2010. p. 9-15. https://doi.org/10.1016/ B978-0-12-374203-2.00169-X.

26. Cringle SJ, Yu DY, Yu PK, Su EN. Intraretinal oxygen consumption in the rat in vivo. Investig Ophthalmol Vis Sci. 2002;43(6):1922-27.

27. Yu DY, Cringle SJ, Yu PK, Su EN. Intraretinal oxygen distribution and consumption during retinal artery occlusion and graded hyperoxic ventilation in the rat. Investig Ophthalmol Vis Sci. 2007:48(5):2290-96. https://doi.org/10.1167/iovs.06-1197.

28. Yamane N, Miyata K, Samejima T, et al. Ocular Higher-Order Aberrations and Contrast AND. 2004;45(11):3986-90. https://doi.org/10.1167/iovs.04-0629.

29. Sugiura Y, Okamoto F, Okamoto Y, Hiraoka T, Oshika T. Contrast sensitivity and foveal mcrostructure following vitrectomy for epiretinal membrane. Invest Opthalmolog Vis Sci. 2014;55(11):7594.

\section{Publisher's Note}

Springer Nature remains neutral with regard to jurisdictional claims in published maps and institutional affiliations.

Ready to submit your research? Choose BMC and benefit from:

- fast, convenient online submission

- thorough peer review by experienced researchers in your field

- rapid publication on acceptance

- support for research data, including large and complex data types

- gold Open Access which fosters wider collaboration and increased citations

- maximum visibility for your research: over $100 \mathrm{M}$ website views per year

At $\mathrm{BMC}$, research is always in progress.

Learn more biomedcentral.com/submissions 